\title{
Normalization of Height in Girls with Turner Syndrome after Long-Term Growth Hormone Treatment: Results of a Randomized Dose-Response Trial*
}

\author{
THEO C. J. SAS, SABINE M. P. F. DE MUINCK KEIZER-SCHRAMA, \\ THEO STIJNEN, MAARTEN JANSEN, BARTO J. OTTEN, \\ J. J. GERA HOORWEG-NIJMAN, THOMAS VULSMA, GUY G. MASSA, \\ CATRIENUS W. ROUWÉ, H. MAARTEN REESER, WILLEM-JAN GERVER, \\ JOS J. GOSEN, CISKA RONGEN-WESTERLAKEN, AND STENVERT L. S. DROP
}

\author{
Department of Pediatrics, Division of Endocrinology (T.C.J.S., S.M.P.F.d.M.K-S., S.L.S.D.) Sophia \\ Children's Hospital, 3015 GJ Rotterdam; Department of Epidemiology and Biostatistics (T.S.), \\ Erasmus University Rotterdam, 3015 GJ Rotterdam; Wilhelmina Children's Hospital (M.J.), 3584 EA \\ Utrecht; Sint Radboud University Hospital (B.J.O.), 6525 GA Nijmegen; Free University Hospital \\ (J.J.G.H-N.), 1081 HV Amsterdam; Emma Children's Hospital, Academic Medical Center (T.V.), 7105 \\ AZ Amsterdam; Medical University Center (G.G.M.), 2333 AA Leiden; Beatrix Children's Hospital \\ (C.W.R.), 9713 EZ Groningen; Juliana Children's Hospital (H.M.R.), 2566 ER The Hague; Academic \\ Hospital (W.J.G.), 6202 AZ Maastricht; Rijnland Hospital (J.J.G.), 2353 GA Leiderdorp; Canisius- \\ Wilhelmina Hospital (C.R-W.), 6532 SZ Nijmegen, the Netherlands
}

\begin{abstract}
Short stature and ovarian failure are the main features in Turner syndrome (TS). To optimize GH and estrogen treatment, we studied 68 previously untreated girls with TS, age 2-11 yr, who were randomly assigned to one of three GH dosage groups: group A, 4 IU/ $\mathrm{m}^{2} \cdot$ day $(\approx 0.045 \mathrm{mg} / \mathrm{kg} \cdot$ day $)$; group B, first yr 4 , thereafter $6 \mathrm{IU} / \mathrm{m}^{2} \cdot$ day $(\approx 0.0675 \mathrm{mg} / \mathrm{kg} /$ day $)$; group $\mathrm{C}$, first yr 4 , second yr 6 , thereafter 8 $\mathrm{IU} / \mathrm{m}^{2} \cdot$ day $(\approx 0.090 \mathrm{mg} / \mathrm{kg} \cdot d a y)$. In the first $4 \mathrm{yr}$ of $\mathrm{GH}$ treatment, no estrogens for pubertal induction were given to the girls. Thereafter, girls started with $17 \beta$-estradiol ( $5 \mu \mathrm{g} / \mathrm{kg}$ bw·day, orally) when they had reached the age of $12 \mathrm{yr}$. Subjects were followed up until attainment of adult height or until cessation of treatment because of satisfaction with the height achieved.

Seven-year data of all girls were evaluated to compare the growthpromoting effects of three GH dosages during childhood. After $7 \mathrm{yr}$, $85 \%$ of the girls had reached a height within the normal range for
\end{abstract}

healthy Dutch girls. The 7-yr increment in height SD-score was significantly higher in groups $\mathrm{B}$ and $\mathrm{C}$ than in group $\mathrm{A}$. In addition, we evaluated the data of 32 of the 68 girls who had completed the trial after a mean duration of treatment of $7.3 \mathrm{yr}$ (range, 5.0 - 8.75). Mean (SD) height was $158.8 \mathrm{~cm}(7.1), 161.0 \mathrm{~cm} \mathrm{(6.8),} \mathrm{and} 162.3 \mathrm{~cm} \mathrm{(6.1)} \mathrm{in}$ groups A, B, and C, respectively. The mean (SD) difference between predicted adult height before treatment and achieved height was 12.5 $\mathrm{cm}(2.1), 14.5 \mathrm{~cm} \mathrm{(4.0),} \mathrm{and} 16.0 \mathrm{~cm}$ (4.1) for groups A, B, and C, respectively, being significantly different between group $A$ and group C. GH treatment was well tolerated in all three GH dosage groups.

In conclusion, GH treatment starting in relatively young girls with TS results in normalization of height during childhood, as well as of adult height, in most of the individuals. With this GH and estrogen treatment regimen, most girls with TS can grow and develop much more in conformity with their healthy peers. (JClin Endocrinol Metab 84: $4607-4612,1999$
$S^{\mathrm{t}}$ HORT STATURE and ovarian failure are the main features in Turner syndrome (TS). The median adult height of North European girls with TS is $146.9 \mathrm{~cm}$, being, on average, approximately $20 \mathrm{~cm}$ less than their healthy peers (1, 2). Although these girls are not GH deficient (3), GH administration accelerates growth in a dose-dependent way $(4,5)$. In many countries, TS is an accepted indication for GH treatment, although the effect of GH on adult height is inconsistent (6-11). In most girls with TS, puberty has to be induced by estrogen therapy. The optimal age to start estrogen ther-

Received August 25, 1999. Accepted October 5, 1999.

Address correspondence and requests for reprints to: Theo Sas, M.D., Division of Endocrinology, Sophia Children's Hospital, Dr. Molewaterplein 60, 3015 GJ Rotterdam, the Netherlands. E-mail: sas@alkg.azr.nl.

* This study was supported by Novo Nordisk A/S (Bagsvaerd, Denmark). Four-year results were described earlier in The Journal of Clinical Endocrinology \& Metabolism. A preliminary analysis has been presented at the European Society for Pediatric Endocrinology Meeting in Florence, Italy (1998). apy is still a point of discussion. It has been suggested to postpone estrogen therapy to delay closure of the epiphysial growth plates and, consequently, to prolong the growth phase (9-12). However, delay of pubertal development may have serious psychosocial consequences.

To optimize GH and estrogen treatment, in 1989 we started a randomized dose-response study in 68 girls with TS. Fouryear results were described earlier (5). We now report 7-yr results to compare the long-term growth-promoting effect of $\mathrm{GH}$ in childhood between the three dosage groups. In addition, growth data of the girls who had completed the trial before the end of August 1998 have been evaluated.

\section{Patients and Methods}

\section{Study subjects}

Sixty-eight previously untreated girls with TS were enrolled in a multicenter GH dose-response study. The diagnosis was confirmed by lymphocyte chromosomal analysis. Three girls had a prenatal diagnosis. Inclusion criteria were a chronological age (CA) between 2 and $11 \mathrm{yr}$, 
height below the 50th percentile for healthy Dutch girls (13), and normal thyroid function. Exclusion criteria were: associated endocrine and/or metabolic disorders; growth failure caused by other disorders or emotional deprivation; hydrocephalus; previous use of drugs, which could interfere with GH treatment; and spontaneous puberty (14). Written informed consent was obtained from the parents or custodians, whereas a written assent was obtained in the girls more than $12 \mathrm{yr}$ of age. The study protocol was approved by the ethics committee of each participating center.

\section{Study design}

After stratification for CA and height SD-score for CA girls were randomly assigned to one of three $\mathrm{GH}$ dosage groups: $\mathrm{A},(\mathrm{n}=23)$ receiving $4 \mathrm{IU} / \mathrm{m}^{2}$ body surface day (equivalent to $\left.0.045 \mathrm{mg} / \mathrm{kg}\right) ; \mathrm{B},(\mathrm{n}=$ 23) receiving $4 \mathrm{IU} / \mathrm{m}^{2}$.day in the first $\mathrm{yr}$, followed by $6 \mathrm{IU} / \mathrm{m}^{2}$. day $(\approx 0.0675 \mathrm{mg} / \mathrm{kg} \cdot$ day $) ;$ or $\mathrm{C}(\mathrm{n}=22)$ receiving $4 \mathrm{IU} / \mathrm{m}^{2} \cdot$ day in the first $\mathrm{yr}, 6 \mathrm{IU} / \mathrm{m}^{2}$.day in the second $\mathrm{yr}$, and thereafter $8 \mathrm{IU} / \mathrm{m}^{2} \cdot$ day $(\approx 0.090$ $\mathrm{mg} / \mathrm{kg} \cdot \mathrm{day}$ )

Biosynthetic human GH (Norditropin, Novo Nordisk A/S, Bagsvaerd, Denmark) was given sc once daily at bedtime using a pen injection system. Every 3 months, the total GH dose was adjusted to the calculated body surface. According to the study protocol, the GH treatment was stopped when subjects had grown less than $1 \mathrm{~cm}$ over 6 months. However, when girls were satisfied with their height achieved, they elected to stop GH treatment before study criteria for the termination of treatment had been reached. In the first $4 \mathrm{yr}$ of GH treatment, no estrogens for pubertal induction were given to the girls. After $4 \mathrm{yr}$ of GH treatment, estrogen therapy was started in the girls who were older than $12.0 \mathrm{yr}$ of age; the younger girls started estrogen therapy at a yearly visit after reaching the age of $12 \mathrm{yr} .17 \beta$-Estradiol, $5 \mu \mathrm{g} / \mathrm{kg}$ body weight day, orally, were given in the first $2 \mathrm{yr}, 7.5 \mu \mathrm{g} / \mathrm{kg} \cdot$ day in the third $\mathrm{yr}$, and $10 \mu \mathrm{g} / \mathrm{kg} \cdot$ day thereafter. Cyclic progestagen therapy (Duphaston $5 \mathrm{mg} /$ day in the first 14 days of the month) was added after $2 \mathrm{yr}$ of estrogen therapy. If puberty had developed spontaneously (Tanner breast stage $\geq 2$ ) during the study period and before start of estrogens, no estrogens were given.

Height was measured at baseline and subsequently every 3 months using a Harpenden stadiometer. Four measurements per visit were made by two trained observers (A.v.T. and, subsequently T. Sas), and the mean was used for the analysis. For the adult height evaluation, adult height was defined as the most recent available height after discontinuation of GH treatment. Height was expressed as SD-score using the references for healthy Dutch girls (13) or the references for North European untreated girls with TS (2). At adult height, the height SD-score for TS was calculated using the reference data of $21 \mathrm{yr}$ of age. Target height was adapted from Dutch reference data with the addition of $3 \mathrm{~cm}$ for secular trend: $\mathrm{TH}=1 / 2 \times\left(\mathrm{H}_{\text {mother }}+\mathrm{H}_{\mathrm{father}}-12 \mathrm{~cm}\right)+3 \mathrm{~cm}(13)$. Target range was defined as the TH $\pm 8 \mathrm{~cm}$ (15). During GH treatment pubertal stages were assessed according to Tanner (14). Bone age was determined by the same two observers according to the Tanner and Whitehouse radius, ulna, short-bones score (16). Bone maturation was expressed as the ratio of the change in BA to the change in CA ( $\square$ BA/ $\triangle$ CA). Predicted adult height was calculated with the modified projected adult height method, using the equation of Lyon, adapted to
North European untreated girls with TS $(2,17,18)$. To assess the gain in adult height, the attained adult height was compared with the modified projected adult height before treatment. Blood samples were taken at the start of the study and subsequently every yr for determination of the glycosylated hemoglobin.

\section{Statistical analysis}

Results were expressed as mean (SD), unless indicated otherwise. Differences between the dosage groups were first tested by a linear trend test. In case of a significant result, this was followed by comparisons with Student's $t$ tests. Differences between points in time were tested by paired Student's $t$ tests.

\section{Clinical data and 7-yr results}

The trial started in November 1989. During the first $3 \mathrm{yr}$, three girls, one in each dosage group, dropped out of the study because of noncompliance and were lost to follow-up. In October 1997, the remaining 65 girls had been followed for 7 yr. Table 1 lists the baseline clinical data of these girls. The three dosage groups had similar initial characteristics.

Fig. 1 shows the individual heights of the 65 girls at the start of GH treatment, as well as after $7 \mathrm{yr}$. Twelve girls had completed the trial during the 7-yr study period. After $7 \mathrm{yr}$ of GH treatment, 55 of the 65 girls $(85 \%)$ had a height within the normal range for healthy Dutch girls, whereas only 10 girls $(15 \%)$ had a height just below the 3 rd percentile. Fig. 2 shows the height SD-score of the 65 girls using references of healthy Dutch girls (bottom) and the height SD-score using Turner references (top) during the 7-yr study period. At baseline, the girls in all three groups have a mean height that is normal for untreated North European girls with TS. After 7 yr of GH treatment, the Turner height SD-score in all three groups has increased significantly $(P<0.001)$. The change in sD-score was significantly higher in groups B and C compared with group A [95\% confidence interval (CI): 0.08, 0.95; $P=0.02$ and $95 \%$ CI: $0.38,1.27 ; P=0.001$, respectively]. However, the difference in SD-score between groups $\mathrm{B}$ and $C$ was not statistically significant (95\% CI: $-0.19,0.81, P=$ 0.22 ). The height after 7 yr was $16.5 \mathrm{~cm}$ (3.5) in group A, 19.6 $\mathrm{cm}$ (4.5) in group B, and $21.2 \mathrm{~cm}$ (4.3) in group C, greater than the expected height assuming that these girls would follow their height percentile when they were not treated with GH. Compared with healthy Dutch girls, the mean baseline height of the girls was far below normal (Fig. 2, bottom). After

TABLE 1. Mean (SD) baseline data for each treatment group. Karyotype (45,X; other) is expressed in numbers (percentage) of patients

\begin{tabular}{|c|c|c|c|}
\hline & Group A & Group B & Group C \\
\hline Number of girls & 22 & 22 & 21 \\
\hline Baseline CA (yr) & $6.1(2.1)$ & $6.7(2.4)$ & $6.5(2.4)$ \\
\hline Baseline bone age (yr) & $5.5(2.2)$ & $6.0(2.5)$ & $5.8(2.4)$ \\
\hline $\begin{array}{l}\text { Baseline SD-score for height } \\
\text { (references healthy } \\
\text { Dutch girls) }\end{array}$ & $-2.7(0.9)$ & $-2.4(1.0)$ & $-2.6(1.0)$ \\
\hline $\begin{array}{l}\text { Baseline SD-score for height } \\
\text { (references girls with TS) }\end{array}$ & $0.06(1.03)$ & $0.42(1.05)$ & $0.18(1.06)$ \\
\hline $\begin{array}{l}\text { Baseline modified projected } \\
\text { adult height }(\mathrm{cm})\end{array}$ & $146.0(5.5)$ & $147.9(5.6)$ & $146.6(5.6)$ \\
\hline Target height $(\mathrm{cm})$ & $168.8(6.3)$ & $170.1(6.1)$ & $169.5(5.6)$ \\
\hline Karyotype: $45, \mathrm{X}$ & $18(82 \%)$ & $21(96 \%)$ & $16(76 \%)$ \\
\hline Karyotype: other & $4(18 \%)$ & $1(4 \%)$ & $5(24 \%)$ \\
\hline
\end{tabular}



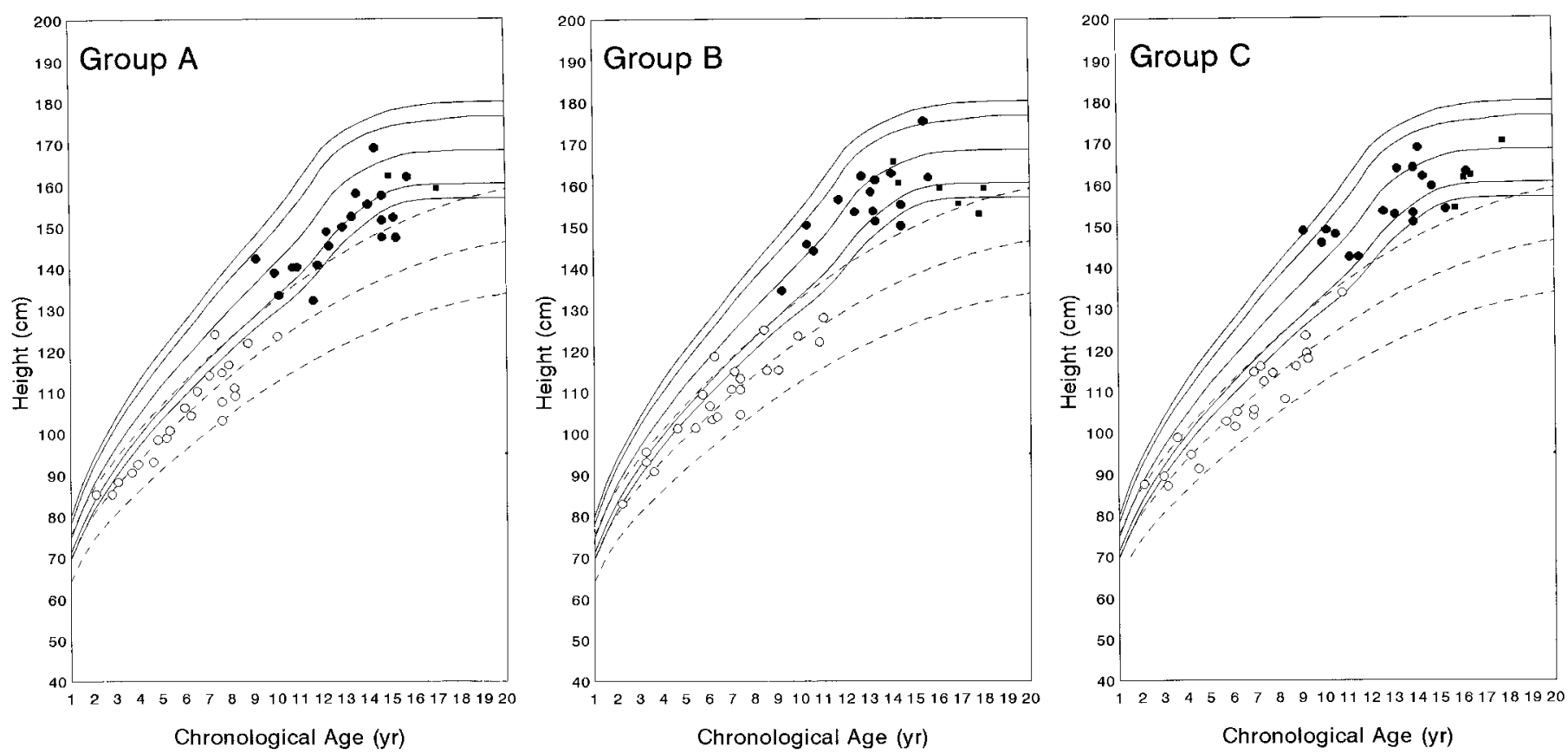

FIG. 1. Individual heights at the start of the study $(\bigcirc)$ and after $7 \mathrm{yr}$ of $\mathrm{GH}$ treatment $(\bullet)$ in groups A, B, and C, respectively. Twelve girls had completed the trial during the 7-yr study period (ם). Reference curves for healthy Dutch girls (3rd, 10th, 50th, 90th, and 97th percentiles) and for untreated girls with TS (North European references; 3rd, 50th, and 97th percentiles) are given.

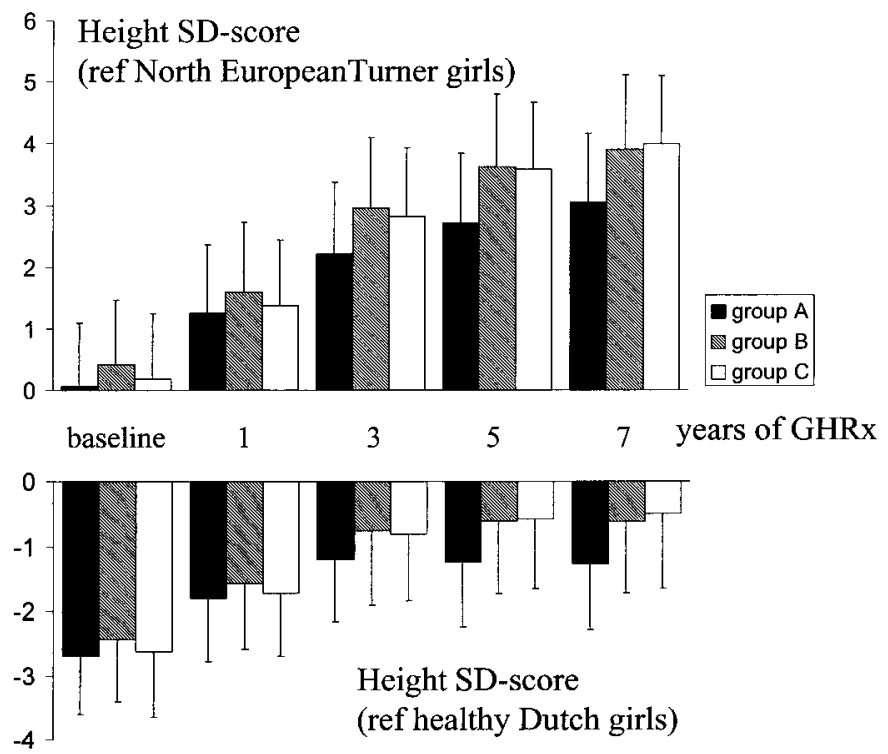

FIG. 2. Height SD-score for CA during $7 \mathrm{yr}$ of GH treatment for groups $\mathrm{A}(\mathrm{n}=22), \mathrm{B}(\mathrm{n}=22)$, and $\mathrm{C}(\mathrm{n}=21)$, respectively. Top, Height compared to references for North European girls with TS. Bottom, Height compared to references for healthy Dutch girls.

$7 \mathrm{yr}$, the mean height sD-score in all three groups had increased to values within the normal range for healthy girls.

To compare skeletal maturation during $7 \mathrm{yr}$ of GH treatment between the three $\mathrm{GH}$ dosage groups, one can determine the bone maturation of all girls still receiving $\mathrm{GH}$ treatment. However, to avoid selection bias, only girls with a CA less than or equal to $14 \mathrm{yr}$ after $7 \mathrm{yr}$ of $\mathrm{GH}$ treatment were included in this analysis (groups A, B, and C, $\mathrm{n}=12,11,12$, respectively). The mean ratio $\square$ bone age (yr) $/ \square \mathrm{CA}$ (yr) over
$7 \mathrm{yr}$ of GH treatment was $1.17(0.14), 1.24(0.16)$, and 1.20 (0.14) in groups A, B, and C, respectively, being significantly higher than 1 ( $P<0.005$ for all three $\mathrm{GH}$ dosage groups). These data indicate an acceleration of bone maturation compared with healthy children. However, no significant differences in bone maturation were found between the three GH dosage groups.

After $7 \mathrm{yr}$ of GH treatment, 35 girls had started estrogen therapy at a mean (SD) CA of $12.9 \mathrm{yr}(0.8)$ and a bone age of $13.2 \mathrm{yr}(0.6)$. Twelve of the 35 girls started estrogen therapy between the CA of 13 and $15 \mathrm{yr}$ because in the first 4-yr study period no estrogens were given, even if these girls were older than $12 \mathrm{yr}$ of age. The other 23 of the 35 girls started estrogen therapy after reaching the age of $12 \mathrm{yr}$. The distribution of the 35 girls over the Tanner breast stages was: 11 girls were M2, 14 girls were M3, 6 girls were M4, and 4 girls were M5 after a mean (SD) duration of estrogen therapy of $1.8 \mathrm{yr}(0.8)$. Five girls did not receive estrogens because of starting spontaneous puberty during GH treatment (at the end of the 7-yr study period, one girl had Tanner breast stage M2, two girls had M3, one girl had M4, and one girl had M5).

\section{Adult height results}

At the end of August 1998, 32 of the 65 girls (groups A, B, and $C, n=10,10,12$, respectively) had completed the study after a mean duration of treatment of $7.3 \mathrm{yr}$ (1.1) (range, 5.0 - 8.75). Twenty girls had discontinued GH treatment because of a height velocity less than $1 \mathrm{~cm}$ over 6 months, whereas 12 girls stopped GH treatment because they were satisfied with their attained height. Table 2 lists the clinical data of these 32 patients. Except for age, the baseline clinical data of these 32 girls were comparable with the baseline data of the 65 girls. Mean height was $158.8 \mathrm{~cm}$ (sD 7.1; range, 
TABLE 2. Mean (SD) baseline and adult height data in 32 girls who have completed the study

\begin{tabular}{|c|c|c|c|}
\hline & Group A & Group B & Group C \\
\hline Number of girls & 10 & 10 & 12 \\
\hline Baseline age (yr) & $7.9(0.9)$ & $8.6(1.6)$ & $8.1(1.4)$ \\
\hline Baseline SD-score for height (references healthy Dutch girls) & $-2.81(1.17)$ & $-2.79(0.72)$ & $-2.84(0.82)$ \\
\hline Baseline SD-score for height (references girls with TS) & $0.09(1.42)$ & $0.17(0.85)$ & $0.10(1.01)$ \\
\hline Baseline modified projected adult height $(\mathrm{cm})$ & $146.2(7.5)$ & $146.6(4.5)$ & $146.2(5.3)$ \\
\hline Target height $(\mathrm{cm})$ & $169.7(4.6)$ & $170.5(5.0)$ & $169.0(4.5)$ \\
\hline Duration GH treatment (months) & $93.3(8.5)$ & $81.3(14.5)$ & $87.0(14.8)$ \\
\hline Age start $17 \beta$-estradiol & $12.7(0.6)$ & $13.3(1.1)$ & $12.9(0.8)$ \\
\hline Last age (yr) & $16.0(0.8)$ & $15.8(1.0)$ & $15.7(0.9)$ \\
\hline Last height $(\mathrm{cm})$ & $158.8(7.1)$ & $161.0(6.8)$ & $162.3(6.1)$ \\
\hline
\end{tabular}

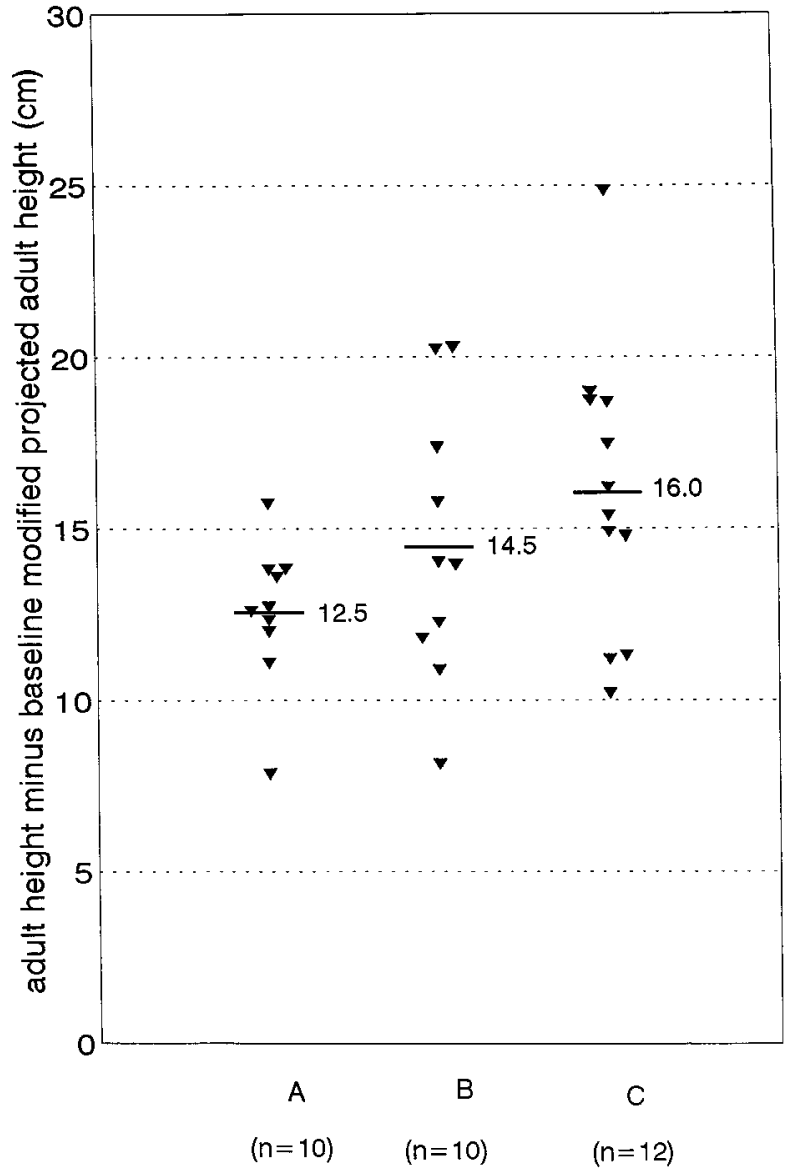

FIG. 3. The most recent height of each subject completing GH treatment relative to each subject's modified projected adult height for groups $A(n=10), B(n=10)$, and $C(n=12)$, respectively. Mean increment in height (in $\mathrm{cm}$ ) relative to modified projected adult height is indicated.

148.3-172.4 cm) in group A, $161.0 \mathrm{~cm}$ (sD 6.8; range, 152.8$176.2 \mathrm{~cm}$ ) in group B, and $162.3 \mathrm{~cm}$ (sD 6.1; range, 154.3-171.2 $\mathrm{cm}$ ) in group C, respectively. Except one girl, all girls (31 of 32) had a height of more than $150 \mathrm{~cm}$. More than half the girls (17 of 32) had a height above $160 \mathrm{~cm}$, and five of them exceeded $170 \mathrm{~cm}$. The mean difference between the target height and the attained height was $10.9 \mathrm{~cm}$ (5.1) for group A,

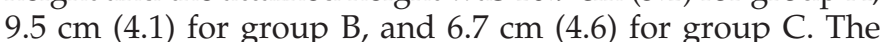
target range was reached in 4 of 10 girls in group A, 4 of 10 girls in group B, and 9 of 12 girls in group C. Fig. 3 shows the attained height of each subject relative to each subject's modified projected adult height. The mean increment in height was $12.5 \mathrm{~cm}$ (sD 2.1; range, $7.8-15.7 \mathrm{~cm}$ ) for group A, $14.5 \mathrm{~cm}$ (sD 4.0; range, $8.1-20.3 \mathrm{~cm}$ ) for group $B$, and $16.0 \mathrm{~cm}$ (sD 4.1; range, $10.2-24.8 \mathrm{~cm}$ ) for group $C$, respectively, being significantly different from baseline $(P<0.001)$. The linear trend test showed a significant positive trend toward a higher gain in height (equal attained height minus baseline modified projected adult height) in the dosage groups receiving a higher $\mathrm{GH}$ dose $(P=0.027)$. The gain in height was significantly higher in group $C$ compared with group $\mathrm{A}(P=$ 0.024), but without significant differences between groups $A$ and $B$ and groups B and C, respectively.

Treatment was well tolerated, and no adverse events were detected that were considered to be drug related. During the study period, glycosylated haemoglobin levels remained within the normal range. In addition, none of the girls developed diabetes mellitus.

\section{Discussion}

This study shows that in girls with TS treatment with biosynthetic GH, even with the "standard" dose of 4 IU/ $\mathrm{m}^{2} \cdot$ day $(\approx 0.045 \mathrm{mg} / \mathrm{kg} \cdot$ day), results in a normalization of height during childhood and a normalization of adult height in most of the girls. The ideal study design to assess the growth-promoting effect of $\mathrm{GH}$ is a randomized controlled trial with an untreated study group until adult height. Because at the start of the present study GH treatment in girls with TS was an accepted indication in the Netherlands, such a trial was not possible. Therefore, a randomized dose-response design was chosen to assess the effect of GH treatment on growth. To determine the effect of GH on adult height, the attained adult height was compared with the individually predicted adult height using the modified projected adult height method based on our own references for untreated Dutch girls with TS $(2,18)$. However, in such a growth analysis, secular trend and errors in adult height prediction have to be taken into account. Remarkably, the growth-promoting effect of $\mathrm{GH}$ found in the present study exceeds the effects of secular trend and prediction errors. After 7 yr of GH treatment, most girls had a height within the normal range for healthy Dutch girls. In addition, in the 32 girls who had reached adult height, the mean height in the three dosage groups was approximately $160 \mathrm{~cm}$. Baseline predicted adult height was exceeded in all subjects, and the mean gain in adult height was well above $10 \mathrm{~cm}$, even in the group receiving the standard GH dose of $4 \mathrm{IU} / \mathrm{m}^{2}$.day. More- 
over, in more than half of the 32 girls, the attained height was within the target range.

As in the study of Rosenfeld et al. (9), some girls discontinued the GH treatment earlier because they were satisfied with their attained height. Although the maximal growthpromoting effect could not be obtained in these girls, such a precocious termination of $\mathrm{GH}$ treatment is the consequence of the good growth response of the treatment.

The results of the present study contrast with reports stating that GH treatment in girls with TS results only in modest increments or have no positive effect at all $(6,19,20)$. In these studies, the age of start of GH treatment was considerably older than in our study. In the study of Rosenfeld et al. (9), however, girls were started at a younger age $(9.1 \mathrm{yr})$ and showed a mean gain in adult height $(8.4 \mathrm{~cm})$ being more comparable with our results. The girls who have reached adult height in our study had a mean age at baseline of 8.2 yr, being even younger than in the study of Rosenfeld et al (9). Therefore, in our opinion, the most important reason of our better results is the fact that GH treatment was started at a younger age compared to earlier studies. Because the girls of our study who are still receiving $\mathrm{GH}$ are even younger than the girls who have already attained their adult height, we expect at least a similar gain in adult height in these younger girls. To start GH treatment at an appropriate age to achieve a normal adult height, early diagnosis of TS is very important. Each physician should consider the diagnosis in every short girl even when Turner stigmata are absent.

In our view, it is very important for the psychosocial wellbeing of the girls to induce the pubertal development in conformity with their healthy peers. Therefore, in the present study, estrogen therapy was started at a pubertal age. However, when estrogen therapy is started before the end of the growth phase one runs the risk of earlier epiphysial closure, and consequently a lower gain in adult height. From the results of the present study we can state that low-dose estrogens at a pubertal age does not interfere with the capability of GH treatment to normalize adult height in most of the girls with TS. Thus, a major outcome of our study is that with these GH and estrogen treatment regimens, most girls with TS can grow and develop much more in conformity with their healthy peers.

Seven-year data demonstrated a higher increment in height in the GH dosage groups receiving 6 or $8 \mathrm{IU} / \mathrm{m}^{2}$-day compared with $4 \mathrm{IU} / \mathrm{m}^{2} \cdot$ day. In the 32 girls who had attained their adult stature, the gain in adult height over the baseline predicted adult height was higher with a GH dose of 8 compared with $4 \mathrm{IU} / \mathrm{m}^{2}$.day $(16.0$ vs. $12.5 \mathrm{~cm})$. However, this difference in gain in adult height is quite small in proportion to the difference in the GH dose between these two groups. In contrast, Carel et al. (21) found an increment in adult height that was twice as high in a study group who received an increasing GH dose (dependent on the height velocity, up to $9 \mathrm{IU} / \mathrm{m}^{2} \cdot$ day) compared to a fixed GH dose (approximately $3.9 \mathrm{IU} / \mathrm{m}^{2}$.day) group (10.6 vs. $5.2 \mathrm{~cm}$ ). However, these increments in adult height in both study groups were even lower compared to the results of our dosage group receiving $4 \mathrm{IU} / \mathrm{m}^{2} \cdot$ day, probably due to the higher baseline age of the girls in that study compared to our study.

In conformity with the study of Carel et al. (21) in which even higher GH dosages were used than in our study, tolerance to all three GH regimens was good. Our 4-yr results of the effects of GH treatment on lipid metabolism showed no unwanted side effects (22). As described in other studies, GH treatment had no adverse effect on glucose metabolism, but the insulin levels had increased significantly after $4 \mathrm{yr}$ of GH treatment compared to baseline levels (22-24). In the present study, we showed that during $7 \mathrm{yr}$ of treatment glycosylated hemoglobin levels stayed within the normal range; an extensive evaluation of the effects of long-term GH treatment on carbohydrate metabolism is described elsewhere (24a). In a previous paper, we showed that $7 \mathrm{yr}$ of GH treatment does not have adverse effects on left ventricular heart dimensions or blood pressure (25).

If higher $\mathrm{GH}$ dosages have proven to be safe on the very long-term and result in a clinically significant higher increment in adult height compared to lower GH dosages, costbenefit evaluations have to be performed. Furthermore, psychological studies are required to evaluate whether the (early) normalization of height is accompanied by an improvement of the psychosocial functioning in childhood as well as in adulthood.

In conclusion, GH treatment starting in relatively young girls with TS results in normalization of height during childhood and normalization of adult height in most of the girls, even using the "standard" GH dose of $4 \mathrm{IU} / \mathrm{m}^{2} \cdot$ day $(\approx 0.045$ $\mathrm{mg} / \mathrm{kg} \cdot \mathrm{day})$, and without unwanted side effects. Higher GH doses may be more effective, but the efficacy on adult height and safety in the very long-term have still to be proven. Induction of puberty with low-dose estrogens can be started at normal pubertal age without interference with the capability of GH treatment to normalize adult height in most of the girls with TS.

\section{Acknowledgments}

Mrs. Ingrid van Slobbe, research-nurse, is gratefully acknowledged for her assistance.

\section{References}

1. Ranke MB, Pflüger H, Rosendahl W, et al. 1983 Turner syndrome: spontaneous growth in 150 cases and review of the literature. Eur J Pediatr. 141:81-88.

2. Karlberg J, Albertsson-Wikland K, Naeraa RW, Rongen-Westerlaken C, Wit JM. 1993 Reference values for spontaneous growth in Turner girls and its use in estimating treatment effects. In: Hibi I, Takano K, eds. Basic and clinical approach to Turner syndrome. Amsterdam: Elsevier Science Publishers BV.; 83-92.

3. Wit JM, Massarano AA, Kamp GA, et al. 1992 Growth hormone (GH) secretion in Turner girls as determined by time series analysis. Acta Endocrinol. 127:7-12.

4. Stahnke N, Stubbe P, Attanasio A, Reinhardt D, Partsch CJ, Sippell WG. 1993 GH therapy alone or together with oxandrolone in 212 patients with Turner syndrome (TS): The German experience. In: Hibi I, Takano K, eds. Basic and clinical approach to Turner syndrome. Amsterdam: Elsevier Science Publishers BV.; 315-322.

5. Teunenbroek van A, Muinck Keizer-Schrama de SMPF, Stijnen T, et al. 1995 Yearly stepwise increments of the growth hormone dose results in a better growth response after four years in girls with Turner syndrome. J Clin Endocrinol Metab. 81:4013-4021.

6. Van den Broeck J, Massa GG, Attanasio A, et al, 1995 Final height after long-term growth hormone treatment in Turner syndrome. J Pediatr. 127:729-735.

7. Massa G, Otten BJ, Muinck Keizer-Schrama SMPF, et al. 1995 Treatment with two growth hormone regimens in girls with Turner syndrome: final height results. Horm Res. 43:144-146.

8. Rongen-Westerlaken C, Wit JM, Muinck Keizer-Schrama SMPF, et al. 1992 Growth hormone treatment in Turner syndrome accelerates growth and skeletal maturation. Eur J Pediatr. 151:477-481. 
9. Rosenfeld RG, Attie KM, Frane J, et al. 1998 Growth hormone therapy of Turner's syndrome: beneficial effect on adult height. J Pediatr. 132:319-324.

10. Haeusler G, Schmitt K, Blümel P, Plöchl E, Waldhör T, Frisch H. 1996 Growth hormone in combination with anabolic steroids in patients with Turner syndrome: effect on bone maturation and final height. Acta Paediatr. 85:1408-1414.

11. Nilsson KO, Albertsson-Wikland K, Alm J, et al. 1996 Improved final height in girls with Turner's syndrome treated with growth hormone and oxandrolone. J Clin Endocrinol Metab. 81:635-640.

12. Naeraa RW, Kastrup KW, Nielsen J. 1993 Treatment in Turner syndrome with a low dose peroral $17 \beta$-estradiol alone, or in combination with growth hormone. In: Hibi I, Takano K, eds. Basic and clinical approach to Turner syndrome. Amsterdam: Elsevier Science Publishers BV.; 209-214.

13. Roede MJ, Wieringen JC. 1985 Growth diagrams 1980. Netherlands third nationwide survey. Tijdschr Soc Gezondh. 63(Suppl):1-34.

14. Tanner JM, Whitehouse R. 1976 Longitudinal standards for height, weightheight, height velocity and stages of puberty. Arch Dis Child. 51:170-179.

15. Muinck Keizer-Schrama SMPF, Boukes FS, Oostdijk W, Rikken B. 1998 Diagnostiek kleine lichaamslengte bij kinderen. Alphen aan de Rijn: Van Zuiden Communications BV

16. Tanner JM, Whitehouse RH, Cameron N, Marshall WA, Healy MJR, Goldstein H. 1983 Assessment of skeletal maturity and prediction of adult height (TW2-method) 2nd ed. London: Academic Press.

17. Lyon AJ, Preece MA, Grant DB. 1985 Growth curve for girls with Turner syndrome. Arch Dis Child. 60:932-935.

18. Teunenbroek A, Stijnen T, Otten B, et al. 1996 A regression method including chronological and bone age for predicting final height in Turner syndrome, with a comparison of existing methods. Acta Paediatr. 85:413-420.

19. Taback SP, Collu R, Deal CL, et al. 1996 Does growth hormone supplementation affect adult height in Turner's syndrome? Lancet. 348:25-27.
20. Dacou-Voutetakis C, Karavanaki-Karanassiou K, Petrou V, Georgopoulos N, Maniati-Christidi M, Mavrou A. 1998 The growth pattern and final height of girls with Turner syndrome with and without human growth hormone treatment. Pediatrics. 101:663-668.

21. Carel JC, Mathivon L, Gendrel C, Ducret JP, Chaussain JL. 1998 Near normalization of final height with adapted doses of growth hormone in Turner's syndrome. J Clin Endocrinol Metab. 83:1462-1466.

22. Teunenbroek van A, Muinck Keizer-Schrama de SMPF, Aanstoot HJ, Stijnen Th, Hoogerbrugge N, Drop SLS. 1999 Carbohydrate and lipid metabolism during various growth hormone dosing regimens in girls with Turner syndrome. Metabolism. 48:7-14.

23. Weise M, James D, Leitner CH, Hartmann KKP, Bohles HJ, Attanasio A. 1993 Glucose metabolism in Ullrich-Turner syndrome: long-term effects of therapy with human growth hormone. Horm Res. 39:36-41.

24. Wilson DM, Rosenfeld RG, and the Genentech Turner Collaborative Group. 1991 Effect of GH and oxandrolone on carbohydrate and lipid metabolism. In: Ranke MB, Rosenfeld R, eds. Turner syndrome: growth promoting therapies. Amsterdam: Elsevier Science Publishers B.V. (Biomedical Division); 269-274.

24a.Sas TCJ, de Muinck Keizer-Schrama SMPF, Stijnen T, Aanstoot HJ, Drop SLS. 1999 Carbohydrate metabolism during long-term growth hormone treatment and after discontinuation of growth hormone treatment in girls with Turner syndrome participating in a randomized dose-response study. J Clin Endocrinol Metab. In press

25. Sas TC, Cromme-Dijkhuis AH, de Muinck Keizer-Schrama SM, Stijnen T, van Teunenbroek A, Drop SLS. The effects of long-term growth hormone treatment on cardiac left ventricular dimensions and blood pressure in girls with Turner's syndrome participating in a randomized dose-response study. J Pediatr 135:470-476.

\section{Erratum}

In the article "Time mode of growth hormone (GH) entry into the bloodstream and steady-state plasma GH concentrations, rather than sex, estradiol, or menstrual cycle stage, primarily determine the GH elimination rate in healthy young women and men" by N. Shah et al. (The Journal of Clinical Endocrinology E Metabolism 84:2862-2869), the authors make the following correction to the text.

In Subjects and Methods, the i.v. constant GH infusion dose should read 0.5, 1.5, or $4.5 \mu \mathrm{g} / \mathrm{kg} / 3$ hours. The authors regret the error. 